\title{
Has spring snowpack declined in the Washington Cascades?
}

\author{
P. Mote ${ }^{1}$, A. Hamlet ${ }^{1,2}$, and E. Salathé ${ }^{1}$ \\ ${ }^{1}$ Climate Impacts Group, University of Washington, Seattle, USA \\ ${ }^{2}$ Department of Civil and Environmental Engineering, University of Washington, Seattle, USA
}

Received: 26 June 2007 - Published in Hydrol. Earth Syst. Sci. Discuss.: 5 July 2007

Revised: 27 November 2007 - Accepted: 20 December 2007 - Published: 1 February 2008

\begin{abstract}
Our best estimates of 1 April snow water equivalent (SWE) in the Cascade Mountains of Washington State indicate a substantial (roughly 15-35\%) decline from midcentury to 2006, with larger declines at low elevations and smaller declines or increases at high elevations. This range of values includes estimates from observations and hydrologic modeling, reflects a range of starting points between about 1930 and 1970 and also reflects uncertainties about sampling. The most important sampling issue springs from the fact that half the 1 April SWE in the Cascades is found below about $1240 \mathrm{~m}$, altitudes at which sampling was poor before 1945 . Separating the influences of temperature and precipitation on 1 April SWE in several ways, it is clear that long-term trends are dominated by trends in temperature, whereas variability in precipitation adds "noise" to the time series. Consideration of spatial and temporal patterns of change rules out natural variations like the Pacific Decadal Oscillation as the sole cause of the decline. Regional warming has clearly played a role, but it is not yet possible to quantify how much of that regional warming is related to greenhouse gas emissions.
\end{abstract}

\section{Introduction}

Phase changes of water from ice to liquid are among the most visible results of a warming climate, and include declines in summer Arctic sea ice, the Greenland ice sheet, and most of the world's glaciers (Lemke et al., 2007). These components of the cryosphere have slow response times and take decades to centuries to come into equilibrium with a change in climate. By contrast, seasonal snow cover disappears every year, and therefore each year's snow cover is the product of a single year's climate conditions. This makes changes happen more rapidly but also substantially decreases the signal-tonoise ratio.

Correspondence to: P. Mote

(philip@atmos.washington.edu)
Northern hemisphere spring snow cover has declined about $8 \%$ over the period of record 1922-2005 (Lemke et al., 2007), and the declines have predominantly occurred between the $0^{\circ}$ and $5^{\circ} \mathrm{C}$ isotherms, underscoring the feedbacks between snow and temperature near the freezing point. That is, small amounts of warming can provide the impetus to melt snow, which increases absorption of solar radiation by the underlying surface and provides additional warming. This feedback is particularly strong in spring in sunny lower latitudes, but not as strong in the cloudy Northwest especially in winter. For the mountainous regions of the western U.S., summers are usually dry and snowmelt provides approximately $70 \%$ of annual streamflow. Observations of mountain snowpack in the spring provide important predictions of summer streamflow for agriculture, hydropower, and flood control, among other needs. These mountain snow observations also provide a unique climate record of changes in the mountains, showing for example that the fraction of sites posting declines in April 1 SWE is about $75 \%$ whether one begins the analysis in 1950 or 1960 (Mote et al., 2005; Mote, 2006). Bales et al. (2006), using the driving data for the VIC hydrologic model that is used in this paper as well as in Mote et al. (2005), estimated the fraction of annual precipitation falling between $0^{\circ} \mathrm{C}$ and $-3^{\circ} \mathrm{C}$, what one might call warm snow. The Cascade and Olympic Mountains of Washington and Oregon stand out as having the highest fraction of warm snow in the continental U.S. The enormous importance of snowmelt for western water resources, and the sensitivity of snow accumulation and melt to air temperature, provide strong motivations for better understanding the role that warming has played in regional changes in snowpack. Politicians interested in reducing greenhouse gas emissions have been citing reductions in snowpack as a motivation for doing so.

Additional impetus for this paper came during a discussion at the University of Washington about how much decline the snowpack of the Washington Cascades had actually experienced, a discussion that spilled into the regional news media

Published by Copernicus Publications on behalf of the European Geosciences Union. 
Table 1. Locations and starting year of snow courses used in this study, sorted by elevation. "AM" refers to aerial markers, where snow depth is estimated from aerial photos of a snow stake and SWE is inferred from snow depth.

\begin{tabular}{|c|c|c|c|c|}
\hline name & started & longitude & latitude & elev (m) \\
\hline Meadow Cabins & 1945 & 120.933 & 48.583 & 579 \\
\hline Rocky Creek & 1959 & 121.800 & 48.683 & 640 \\
\hline Beaver Creek Trail & 1944 & 121.200 & 48.833 & 670 \\
\hline S. Fork Thunder Creek & 1959 & 121.667 & 48.600 & 670 \\
\hline Dommerie Flats & 1939 & 121.067 & 47.233 & 670 \\
\hline City Cabin & 1948 & 121.517 & 47.317 & 728 \\
\hline Thunder Basin & 1948 & 120.983 & 48.517 & 731 \\
\hline Tunnel Avenue & 1941 & 121.350 & 47.317 & 746 \\
\hline Toats Coulee & 1959 & 119.733 & 48.850 & 867 \\
\hline Ahtanum Ranger Station & 1941 & 121.017 & 46.517 & 945 \\
\hline Mt. Gardner & 1959 & 121.567 & 47.367 & 1006 \\
\hline Fish Lake & 1943 & 121.567 & 47.517 & 1027 \\
\hline Schreibers Meadow & 1959 & 121.817 & 48.700 & 1036 \\
\hline Freezeout Creek Trail & 1944 & 120.950 & 48.950 & 1067 \\
\hline Marten Lake & 1959 & 121.717 & 48.767 & 1097 \\
\hline Olallie Meadows & 1945 & 121.450 & 47.383 & 1105 \\
\hline Beaver Pass & 1944 & 121.250 & 48.883 & 1121 \\
\hline Dock Butte AM & 1959 & 121.800 & 48.633 & 1158 \\
\hline Stampede Pass & 1943 & 121.333 & 47.283 & 1176 \\
\hline Rusty Creek & 1943 & 119.867 & 48.533 & 1219 \\
\hline Satus Pass & 1957 & 120.683 & 45.983 & 1228 \\
\hline Sasse Ridge & 1944 & 121.050 & 47.367 & 1280 \\
\hline Blewett Pass No. 2 & 1946 & 120.683 & 47.350 & 1301 \\
\hline Upper Wheeler & 1959 & 120.367 & 47.283 & 1341 \\
\hline Salmon Meadows & 1938 & 119.833 & 48.667 & 1371 \\
\hline Watson Lakes & 1959 & 121.583 & 48.667 & 1371 \\
\hline Hurricane & 1949 & 123.533 & 47.967 & 1371 \\
\hline White Pass (E. Side) & 1953 & 121.383 & 46.633 & 1371 \\
\hline Cox Valley & 1959 & 123.483 & 47.967 & 1371 \\
\hline Park Creek Ridge & 1928 & 120.917 & 48.450 & 1402 \\
\hline Bumping Ridge & 1953 & 121.333 & 46.817 & 1402 \\
\hline Rainy Pass & 1930 & 120.717 & 48.567 & 1457 \\
\hline Chewelah & 1958 & 117.583 & 48.283 & 1501 \\
\hline Stemilt Slide & 1959 & 120.383 & 47.283 & 1524 \\
\hline Easy Pass AM & 1959 & 121.433 & 48.867 & 1585 \\
\hline Deer Park & 1949 & 123.250 & 47.950 & 1585 \\
\hline Boyer Mountain & 1946 & 117.433 & 48.200 & 1600 \\
\hline Little Meadows AM & 1927 & 120.900 & 48.200 & 1608 \\
\hline Cayuse Pass & 1940 & 121.533 & 46.867 & 1615 \\
\hline Jasper Pass AM & 1959 & 121.400 & 48.783 & 1646 \\
\hline Paradise Pillow & 1940 & 121.717 & 46.800 & 1676 \\
\hline Mutton Creek No. 1 & 1938 & 119.867 & 48.667 & 1737 \\
\hline Devils Park & 1950 & 120.850 & 48.750 & 1798 \\
\hline Lyman Lake & 1928 & 120.917 & 48.200 & 1798 \\
\hline Green Lake & 1941 & 121.167 & 46.550 & 1829 \\
\hline Corral Pass & 1940 & 121.467 & 47.017 & 1829 \\
\hline Miners Ridge & 1928 & 120.983 & 48.167 & 1890 \\
\hline Harts Pass & 1941 & 120.650 & 48.717 & 1981 \\
\hline Cloudy Pass AM & 1927 & 120.917 & 48.200 & 1981 \\
\hline
\end{tabular}

and the national blogosphere. Questions raised included the effects of sampling bias, suitability of linear fits for describing change over time, effects of the choice of period of analysis, and the (possibly competing) influences of Pacific climate variability and human-induced global climate change on regional temperature, precipitation, and snowpack. This paper explicitly addresses most of these issues, but the role of human-induced climate changes at this scale is not yet quantifiable. We emphasize that regional warming has played a significant, even dominant, role in the decline of the region's snowpack, as shown particularly in the comparison of lowelevation and high-elevation changes. Linking those changes to global greenhouse gases is a "signal-detection" exercise, which has been successfully conducted on the scale of the western U.S. (Stott, 2003), but not for spatial scales as small as western Washington.

\section{Data and methods}

Snow surveys have been conducted at over a thousand carefully chosen and marked locations, or "snow courses", in western North America for decades. Since the purpose of the snow surveys was water supply forecasting, the measurements of SWE were most prevalent initially near the date of peak SWE, 1 April. Over time the sites were typically visited more frequently, usually at monthly intervals from 1 January to 1 June. Automated sites began to be used in the 1980s and in some cases replaced snow courses. For Washington's Cascades (west of $120^{\circ}$ longitude) and Olympics, 49 long term records are available (Fig. 1, Table 1). Spatial coverage is uneven, and was especially uneven before 1938 when all snow courses (and aerial markers) were at high elevation in the North Cascades.

The data are provided by the Natural Resources Conservation Service (NRCS) of the US Department of Agriculture (http://www.wcc.nrcs.usda.gov/snow/snowhist. html). Climate data came from the Western Regional Climate Center (http://www.wrcc.dri.edu/cgi-bin/divplot1_ form.pl?4504). The North Pacific Index (NPI) was obtained from http://www.cgd.ucar.edu/cas/jhurrell/indices.html. Detailed consideration of individual time series is beyond the scope of this paper, but users can plot maps of linear trends and also time series at individual sites at http://www.climate. washington.edu/trendanalysis/.

The smoothing performed in some of the figures uses the locally weighted regression ("loess") scheme (Cleveland, 1993) with partial reflection. Loess computes each value for the smoothed time series by performing a least-squares linear fit on weighted adjacent data, where the analyst determines a suitable window to define adjacent and the weighting favors closer points. The smoothing parameter $\alpha$ is chosen so that the residuals have very little low-frequency variability; in this case $\alpha=0.6$. To handle variations near the endpoints, a linear combination of two loess-smoothed versions is used: first, the original time series, for which the end points are somewhat weakly constrained, and second, the middle third of a time series formed by reflecting the original time series $\left(\mathrm{x}_{1}, \ldots \mathrm{x}_{j}\right)$ about its endpoints $\left(\mathrm{x}_{j} \ldots \mathrm{x}_{1}, \mathrm{x}_{1}, \ldots \mathrm{x}_{j}, \mathrm{x}_{j} \ldots \mathrm{x}_{1}\right)$ with the result that the first derivative of the curve must be zero 


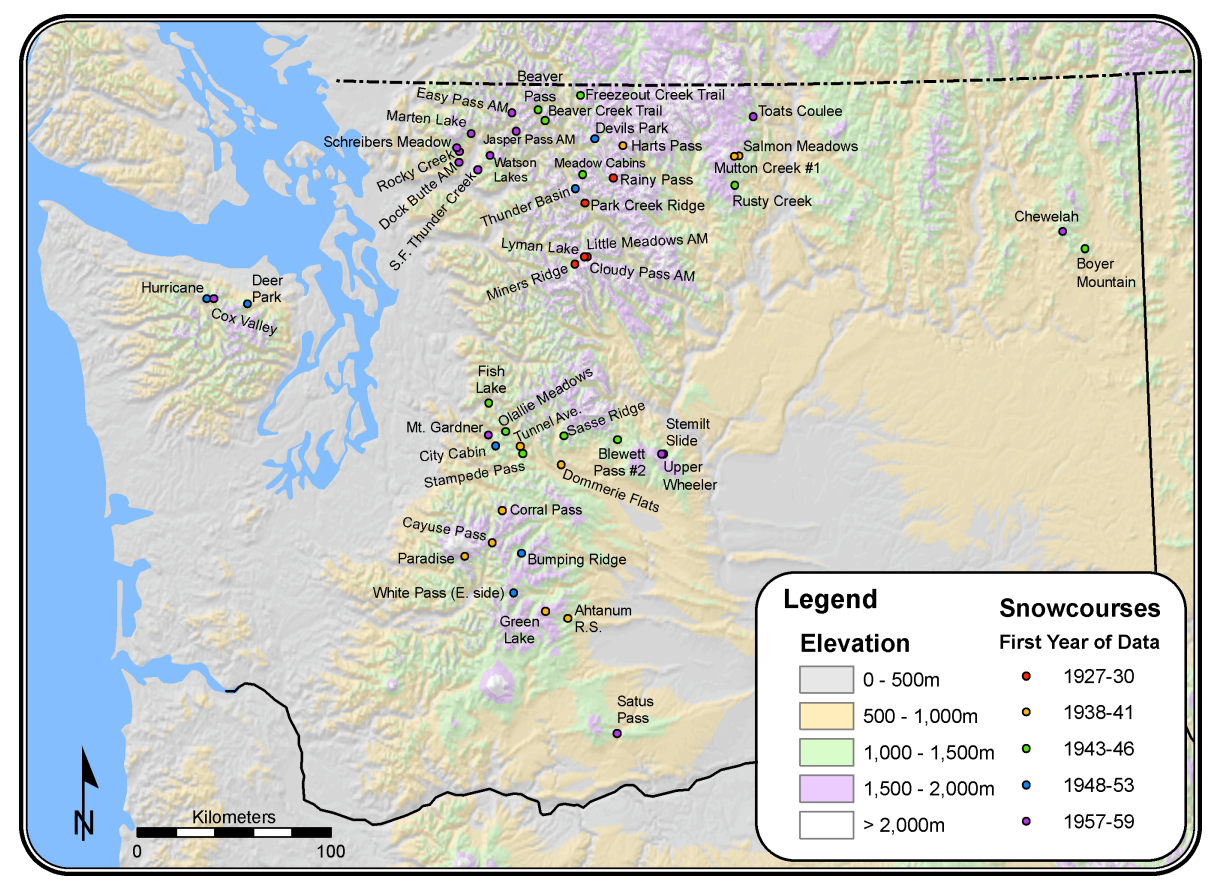

Fig. 1. Map of Washington snow courses.

at the endpoints. This "partial reflection" approach seems to produce the best results at the endpoints.

For calculating statistical significance, a two-sided t-test $(p<0.05)$ is used, and degrees of freedom are first estimated by checking for autocorrelation. In the time series shown here, the structure of the autocorrelation function is such that the number of degrees of freedom is approximately the number of data points (using the method of Bretherton et al., 1999).

\section{Simulation with the VIC hydrology model}

Physically based hydrologic models can be used to achieve some of the goals of this study, by providing spatially complete fields and also by evaluating the climatic factors behind the variability and trends in snowpack. In this study (as in Mote et al., 2005, and Hamlet et al., 2005) we use the Variable Infiltration Capacity (VIC) hydrologic model (Liang et al., 1994; Cherkauer and Lettenmaier, 2003) implemented over the western U.S. at 1/8th degree spatial resolution. As inputs to the VIC model, we used a gridded dataset of daily precipitation and maximum and minimum temperature (Hamlet and Lettenmaier 2005), at the same 1/8th degree resolution, from 1915 to 2003. Spatial interpolation of daily data from the Cooperative weather (Coop) network, with terrain-dependent algorithms, provide the spatial coverage. The temporal characteristics of the dataset are nudged toward the monthly values from the climate-quality dataset from the Historical Climatology Network (HCN) (Karl et al., 1990).
The methods used to produce the driving data, and evaluation of the resulting hydrologic simulations using observed streamflow records, are reported in more detail by Hamlet and Lettenmaier (2005).

The VIC simulation was conducted at a daily time step for the water balance and at a time step of one hour for the snow model. To derive the hourly forcing for the snow model, VIC calculates some elements of the hourly-resolution snow accumulation and melt in each day by estimating meteorological drivers on a $24 \mathrm{~h}$ basis. Daily total precipitation from the driving data is divided equally among the 24 hourly periods, and the diurnal cycle of temperature is estimated from the daily Tmax and Tmin values in the driving data by assuming that Tmax and Tmin occur at a fixed time of day, and adjusting splines (based on empirical data) in order to approximate temperatures the rest of the time. Similarly, incoming solar radiation is estimated for each hour, based on empirical relationships keyed to length of day and solar angle. These estimated hourly drivers are then used to drive the snow model. The 24 hourly values of accumulation and melt are then aggregated to the 24-h water balance time step. Additional details on the hydrologic model and its implementation are reported by Hamlet et al. (2005).

Using VIC simulations of snow over the Western U.S., Mote et al. (2005) corroborated observed trends in snowpack derived from snow course observations from 19501997. The model was shown to do a remarkably good job of reproducing topographic gradients in snowpack trends over the West as a whole and particularly in the Cascades in the Pacific Northwest. Based on this evaluation of the model, 


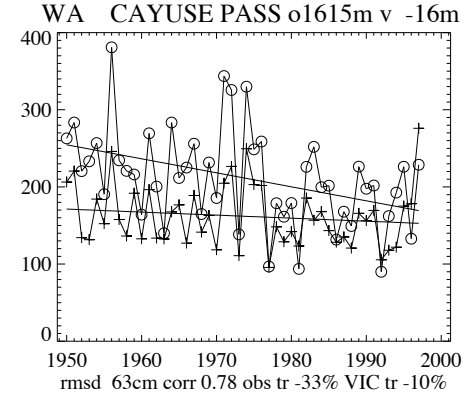

WA CORRAL PASS PILLOW o1829m v $-461 \mathrm{~m}$

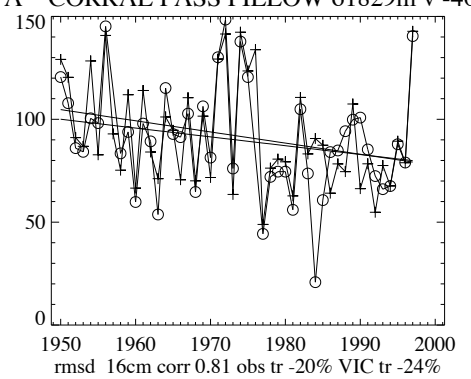

WA DEVILS PARK o1798m v $-739 \mathrm{~m}$

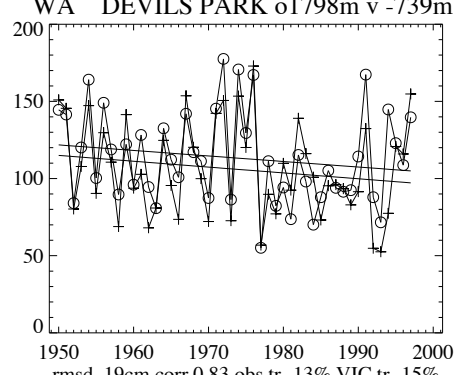

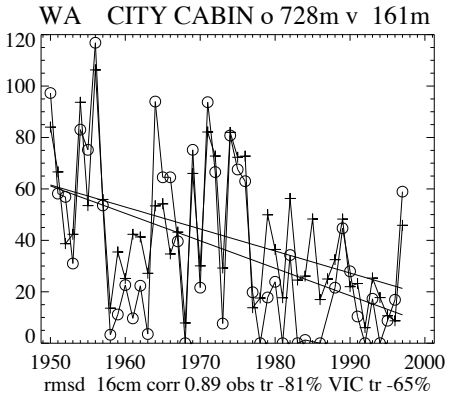
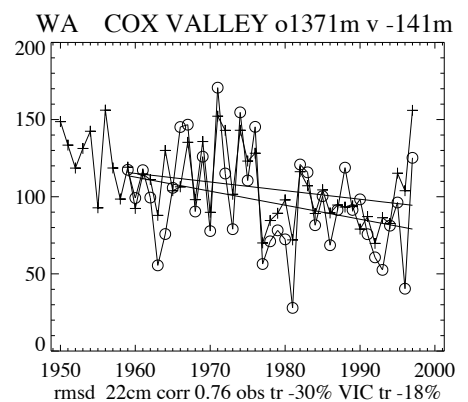

WA DOCK BUTTE AM o1158m v $-73 \mathrm{~m}$

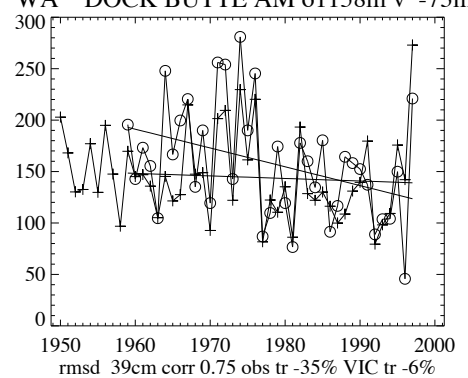

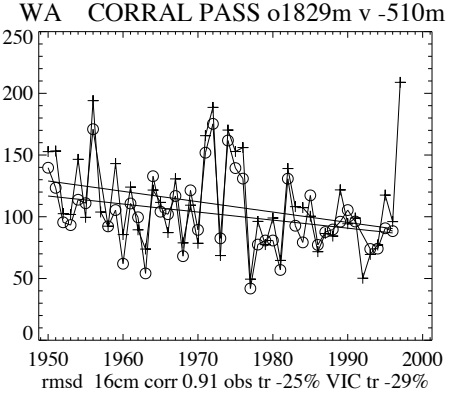

WA DEER PARK $01585 \mathrm{~m} \mathrm{v}-588 \mathrm{~m}$
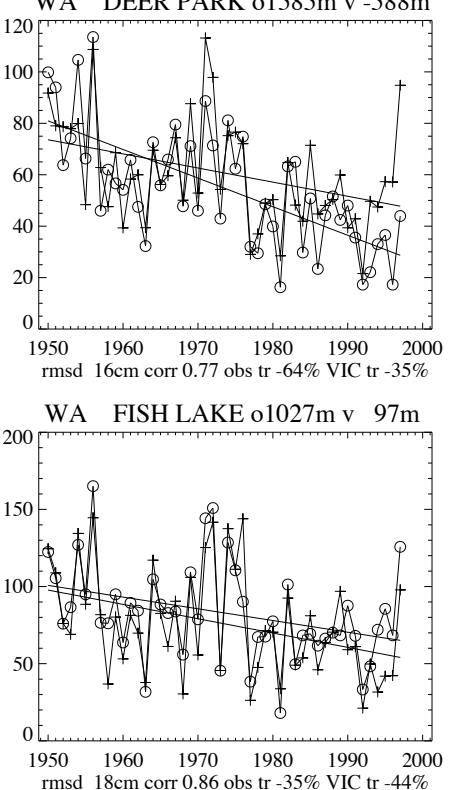

Fig. 2. Observed (o) and VIC simulated (+) 1 April SWE at nine of the snow courses in Washington for 1950-1997. Each frame includes statistics about the elevation $\mathbf{o}$ of the snow course and the difference in elevation $\mathbf{v}$ between the VIC grid cell and the snow course (positive means VIC higher), and statistics that also appear in Table 2. Data are given in centimeters of SWE.

the simulations were extended to 1915-2003 and long term trends in snowpack for several different periods from 19152003 were examined (Hamlet et al., 2005). That study also examined, in detail, the relative roles of temperature and precipitation trends on snowpack trends in each period.

We now examine the performance of the VIC model at the snow courses in Washington over the period 1950-1997. This examination will provide a better understanding of the strengths and weaknesses of VIC and snow courses in estimating regionally averaged SWE, and has not previously been presented at this level of detail. Note first that there are several reasons why the SWE simulated by VIC and the SWE measured at a snow course might differ: terrain, temporal offsets, interpolation of driving data, spurious trends in driving data, and land-cover change at the snow course. These are discussed more by Mote et al. (2005). First, while a VIC grid cell includes 15 snow "bands" with different elevation and land cover over a roughly $10 \times 12 \mathrm{~km}$ area, a snow course reports the snowpack at a specific site in terrain that may or may not be representative of a larger area, though the locations for snow courses are chosen with the goal of representing SWE over a significant portion of a watershed. In a comparison of ground-based and remotely sensed snow properties over an area roughly the size of a VIC grid cell around six SNOTEL sites, Molotch and Bales (2005) found differences in SWE of as much as a factor of two. Second, the actual date of a snow course measurement can be several days before 1 April, so a storm or melt event between the observation date and the 1 April VIC date could introduce a large difference. Third, VIC uses weather data from stations that may be $50 \mathrm{~km}$ or more from the grid cell and may not represent local hydroclimatic conditions despite the efforts of the terrain-dependent algorithm to do so. Fourth, the driving data (especially precipitation) might contain spurious trends owing, for example, to growth of trees over a rain gauge; efforts are made in constructing the $\mathrm{HCN}$ dataset to find and correct such sources of error, but some undoubtedly remain. Finally, changes in land cover (e.g., incursion 
Table 2. Comparison of VIC and observed 1 April SWE, 1950-1997.

\begin{tabular}{|c|c|c|c|c|}
\hline snow course & rms difference & correlation & observed trend & VIC trend \\
\hline Ahtanum R.S. & $8 \mathrm{~cm}$ & 0.71 & $-39 \%$ & $-54 \%$ \\
\hline Beaver Creek Trail & $29 \mathrm{~cm}$ & 0.64 & $-51 \%$ & $-7 \%$ \\
\hline Beaver Pass & $26 \mathrm{~cm}$ & 0.60 & $-46 \%$ & $0 \%$ \\
\hline Big Boulder Creek & $13 \mathrm{~cm}$ & 0.84 & $-31 \%$ & $-34 \%$ \\
\hline Blewett Pass No. 2 & $8 \mathrm{~cm}$ & 0.87 & $-39 \%$ & $-43 \%$ \\
\hline Boyer Mountain & $34 \mathrm{~cm}$ & 0.84 & $-3 \%$ & $-33 \%$ \\
\hline Bumping Ridge Pillow & $15 \mathrm{~cm}$ & 0.85 & $-14 \%$ & $-15 \%$ \\
\hline Bunchgrass Meadow & $13 \mathrm{~cm}$ & 0.83 & $-20 \%$ & $-21 \%$ \\
\hline Cayuse Pass & $63 \mathrm{~cm}$ & 0.78 & $-33 \%$ & $-10 \%$ \\
\hline City Cabin & $16 \mathrm{~cm}$ & 0.89 & $-81 \%$ & $-65 \%$ \\
\hline Corral Pass & $16 \mathrm{~cm}$ & 0.91 & $-25 \%$ & $-29 \%$ \\
\hline Cox Valley & $22 \mathrm{~cm}$ & 0.76 & $-30 \%$ & $-18 \%$ \\
\hline Deer Park & $16 \mathrm{~cm}$ & 0.77 & $-64 \%$ & $-35 \%$ \\
\hline Devils Park & $19 \mathrm{~cm}$ & 0.83 & $-13 \%$ & $-15 \%$ \\
\hline Dock Butte AM & $39 \mathrm{~cm}$ & 0.75 & $-35 \%$ & $-6 \%$ \\
\hline Fish Lake & $18 \mathrm{~cm}$ & 0.86 & $-35 \%$ & $-44 \%$ \\
\hline Freezout Creek Trail & $28 \mathrm{~cm}$ & 0.66 & $-45 \%$ & $-7 \%$ \\
\hline Green Lake & $16 \mathrm{~cm}$ & 0.78 & $+2 \%$ & $+11 \%$ \\
\hline Harts Pass & $18 \mathrm{~cm}$ & 0.78 & $-28 \%$ & $-2 \%$ \\
\hline Hurricane Ridge & $18 \mathrm{~cm}$ & 0.80 & $-71 \%$ & $-35 \%$ \\
\hline Lake Cle Elum & $9 \mathrm{~cm}$ & 0.89 & $-89 \%$ & $-65 \%$ \\
\hline Lyman Lake & $27 \mathrm{~cm}$ & 0.80 & $-6 \%$ & $-11 \%$ \\
\hline Marten Lake & $44 \mathrm{~cm}$ & 0.68 & $-5 \%$ & $+3 \%$ \\
\hline Miners Ridge Pillow & $23 \mathrm{~cm}$ & 0.87 & $-11 \%$ & $-19 \%$ \\
\hline Mount Gardner & $17 \mathrm{~cm}$ & 0.83 & $-56 \%$ & $-50 \%$ \\
\hline Mutton Creek No. 1 & $10 \mathrm{~cm}$ & 0.76 & $-30 \%$ & $-14 \%$ \\
\hline Olallie Meadows & $31 \mathrm{~cm}$ & 0.84 & $-58 \%$ & $-37 \%$ \\
\hline Paradise & $36 \mathrm{~cm}$ & 0.84 & $-24 \%$ & $-10 \%$ \\
\hline Park Creek Ridge & $22 \mathrm{~cm}$ & 0.80 & $-20 \%$ & $-20 \%$ \\
\hline Rainy Pass & $18 \mathrm{~cm}$ & 0.72 & $-29 \%$ & $-5 \%$ \\
\hline Rocky Creek & $25 \mathrm{~cm}$ & 0.78 & $-23 \%$ & $-15 \%$ \\
\hline Rusty Creek & $4 \mathrm{~cm}$ & 0.82 & $-56 \%$ & $-25 \%$ \\
\hline South Fork Thunder Creek & $9 \mathrm{~cm}$ & 0.77 & $-68 \%$ & $-8 \%$ \\
\hline Salmon Meadows & $6 \mathrm{~cm}$ & 0.80 & $-40 \%$ & $-14 \%$ \\
\hline Schreibers Meadow & $34 \mathrm{~cm}$ & 0.76 & $-40 \%$ & $-5 \%$ \\
\hline Stampede Pass Pillow & $22 \mathrm{~cm}$ & 0.84 & $-20 \%$ & $-28 \%$ \\
\hline Stemilt Slide & $8 \mathrm{~cm}$ & 0.75 & $-17 \%$ & $-17 \%$ \\
\hline Thunder Basin & $42 \mathrm{~cm}$ & 0.56 & $-36 \%$ & $-11 \%$ \\
\hline Tunnel Avenue & $14 \mathrm{~cm}$ & 0.87 & $-56 \%$ & $-52 \%$ \\
\hline Upper Wheeler & $9 \mathrm{~cm}$ & 0.64 & $-43 \%$ & $-17 \%$ \\
\hline Watson Lakes & $38 \mathrm{~cm}$ & 0.69 & $-34 \%$ & $-5 \%$ \\
\hline White Pass (East Side) & $16 \mathrm{~cm}$ & 0.92 & $-21 \%$ & $-15 \%$ \\
\hline median & $18 \mathrm{~cm}$ & 0.80 & \multicolumn{2}{|c|}{ median difference $-15 \%$} \\
\hline
\end{tabular}

of forest into a previously open area) at the site of the snow course may also introduce trends that are not present in the VIC simulation, which presumes constant land cover. For all these reasons, and probably more, we would not expect a close match between the mean VIC grid cell value and the mean snow course value nor between the trends.
Despite these potential sources of differences between VIC SWE and observed SWE, Table 2 and Fig. 2 show a strong correspondence at about three-quarters of the snow courses examined. Correlations are fairly high, with a median of 0.8 , rms differences are typically a small fraction of the mean, with a median of $18 \mathrm{~cm}$, and the median absolute difference in the trends is $16 \%$. For about a quarter of the sites, trends disagree by more than $26 \%$ as with Deer Park 

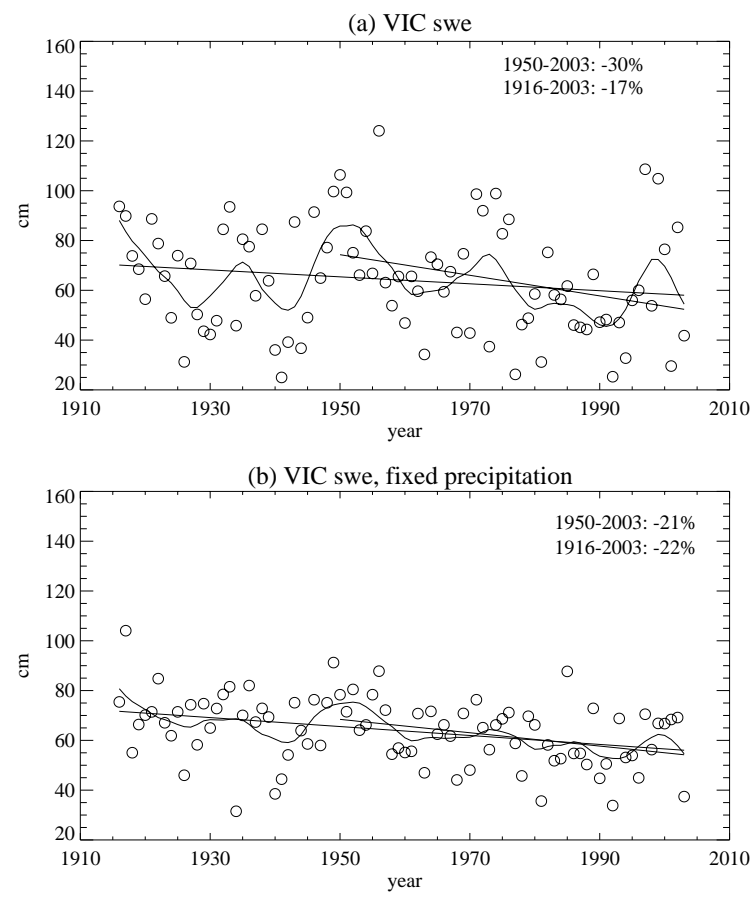

Fig. 3. 1 April SWE simulated by VIC, averaged over the domain of the Cascades and Olympics for (a) the full simulation and (b) a temperature-only simulation, with linear fits and loess smoothing for the time periods indicated.

and Dock Butte aerial marker (AM) shown here. From this analysis it is impossible to deduce which of the reasons just listed is responsible for the discrepancies between VIC and observations. The correspondence at the majority of sites, though, combined with the previously demonstrated success of VIC at simulating streamflow in this region, provides a strong basis for using VIC to produce spatially averaged estimates of total 1 April SWE.

Figure 3a shows the results of spatially averaging the VIC 1 April SWE over the Cascades domain for the 1916-2003 period of record. Note that a number of low-elevation grid cells with no snow on 1 April are included in the domain for averaging, which produces a much lower average SWE than the observed time series we construct below. The interannual variability of the time series shown in Fig. $3 \mathrm{a}$ is substantial, with a coefficient of variation of 0.35 . Highest 1 April SWE occurred in 1956, followed by 1997, 1950, and 1999; very low values occurred in 1941, 1977, and 1992. The smooth curve shows the interdecadal variability, with relatively snowy periods centered around 1950, 1970, and 1999, and relatively snow-poor periods centered around 1992 and 1926. A linear fit to the VIC data for the 1916-2003 period of record gives a decline of $16 \%$ despite an increase in statewide average Nov-Mar precipitation of $16 \%$.

In order to elucidate the climatic factors behind these changes, we examine also a simulation discussed by Hamlet et al. (2005) in which the interannual variability in
Table 3. Linear trend (\%) from starting year to 2003 for observations and VIC, with 5\% and 95\% confidence levels of the trend. For some years, indicated by ' $\mathrm{m}$ ', data are insufficient to perform the calculation.

\begin{tabular}{|c|c|c|c|c|c|c|}
\hline \multirow{2}{*}{ starting yr } & \multicolumn{3}{|c|}{ observations } & \multicolumn{3}{|c|}{ VIC } \\
\hline & $5 \%$ & mean & $95 \%$ & $5 \%$ & mean & $95 \%$ \\
\hline 1935 & -15 & 5 & 27 & -42 & -20 & 1 \\
\hline 1936 & $\mathrm{~m}$ & $\mathrm{~m}$ & $\mathrm{~m}$ & -42 & -19 & 3 \\
\hline 1937 & $\mathrm{~m}$ & $\mathrm{~m}$ & $\mathrm{~m}$ & -41 & -18 & 5 \\
\hline 1938 & -15 & 1 & 18 & -42 & -19 & 4 \\
\hline 1939 & -18 & 0 & 17 & -41 & -17 & 7 \\
\hline 1940 & -25 & -7 & 10 & -42 & -17 & 6 \\
\hline 1941 & -37 & -9 & 8 & -45 & -21 & 2 \\
\hline 1942 & -39 & -12 & 4 & -49 & -26 & -3 \\
\hline 1943 & -44 & -15 & 1 & -51 & -29 & -7 \\
\hline 1944 & -47 & -18 & 0 & -50 & -28 & -5 \\
\hline 1945 & -53 & -25 & -7 & -53 & -32 & -10 \\
\hline 1946 & -45 & -27 & -10 & -56 & -34 & -13 \\
\hline 1947 & -44 & -26 & -8 & -54 & -32 & -10 \\
\hline 1948 & -47 & -29 & -10 & -56 & -33 & -11 \\
\hline 1949 & -48 & -29 & -11 & -56 & -33 & -10 \\
\hline 1950 & -47 & -28 & -9 & -53 & -30 & -6 \\
\hline 1951 & -46 & -26 & -6 & -50 & -25 & 0 \\
\hline 1952 & -45 & -25 & -5 & -46 & -21 & 4 \\
\hline 1953 & -45 & -25 & -4 & -46 & -19 & 6 \\
\hline 1954 & -45 & -24 & -3 & -46 & -19 & 7 \\
\hline 1955 & -43 & -21 & 0 & -45 & -17 & 11 \\
\hline 1956 & -42 & -20 & 1 & -45 & -16 & 12 \\
\hline 1957 & -37 & -15 & 7 & -34 & -5 & 23 \\
\hline 1958 & -37 & -14 & 9 & -35 & -4 & 24 \\
\hline 1959 & -40 & -17 & 6 & -36 & -6 & 26 \\
\hline 1960 & -40 & -16 & 7 & -36 & -5 & 26 \\
\hline 1961 & -42 & -19 & 4 & -39 & -8 & 23 \\
\hline 1962 & -43 & -18 & -6 & -39 & -7 & 24 \\
\hline 1963 & -45 & -20 & 4 & -41 & -7 & 25 \\
\hline 1964 & -49 & -26 & -2 & -45 & -13 & 17 \\
\hline 1965 & -47 & -23 & 1 & -45 & -11 & 21 \\
\hline 1966 & -47 & -22 & 2 & -44 & -9 & 24 \\
\hline 1967 & -47 & -21 & 3 & -45 & -10 & 25 \\
\hline 1968 & -46 & -19 & -7 & -45 & -8 & 28 \\
\hline 1969 & -49 & -22 & 4 & -50 & -13 & 22 \\
\hline 1970 & -47 & -19 & 8 & -48 & -10 & 27 \\
\hline 1971 & -50 & -22 & 5 & -53 & -15 & 22 \\
\hline 1972 & -44 & -14 & 15 & -45 & -5 & 35 \\
\hline 1973 & -35 & -4 & 26 & -37 & 5 & 49 \\
\hline 1974 & -39 & -9 & 21 & -43 & -1 & 40 \\
\hline 1975 & -26 & 4 & 35 & -30 & 14 & 60 \\
\hline
\end{tabular}

precipitation is removed from the driving dataset. This way, interannual variability in SWE is produced primarily from variations in temperature. The result (Fig. 3b) has substantially less interannual variability, and slightly larger trend (22\%). Trends since 1950 were larger, but again were dominated by temperature, not by precipitation. 
(a)

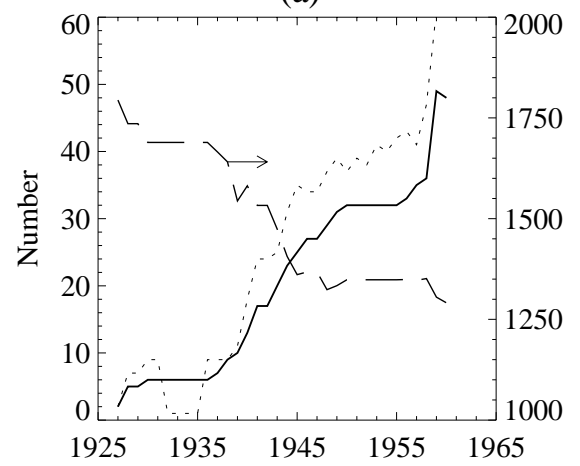

(d)

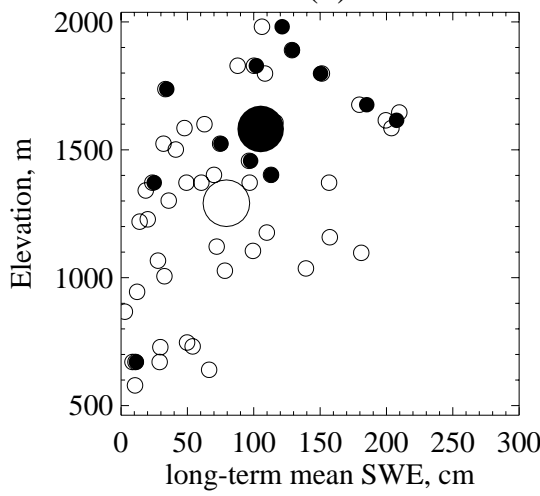

(b) Trends since $1940(1930,+)$

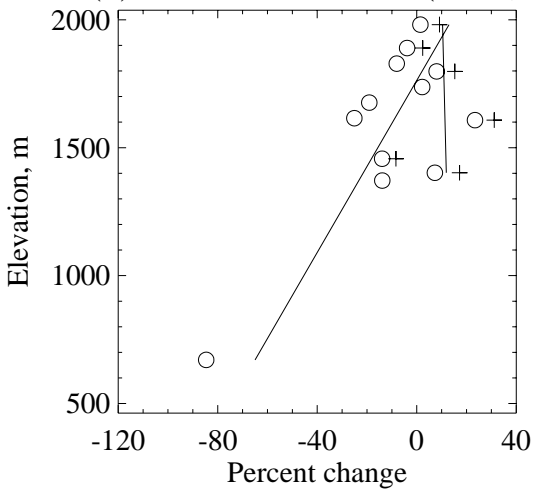

(e) Trends since 1960

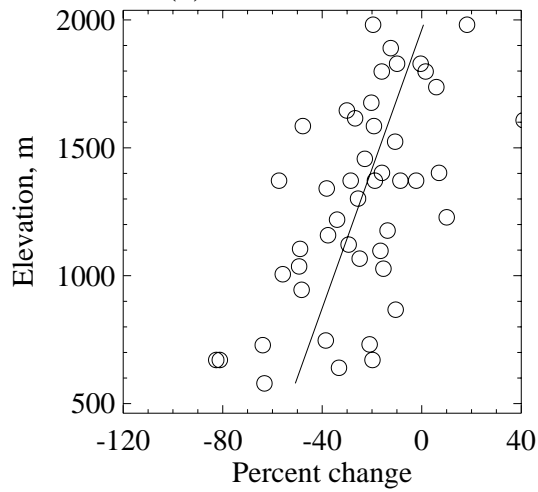

(c) Trends since 1950

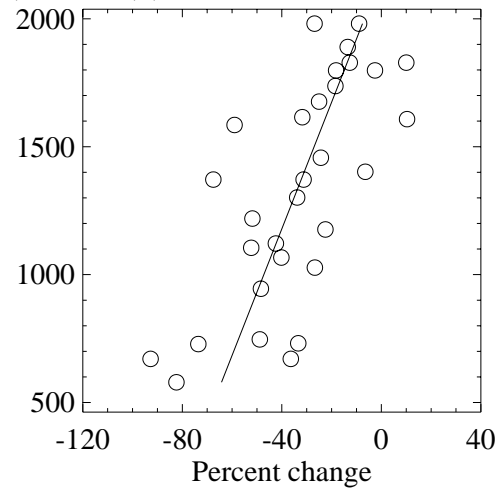

(f) Trends since 1970

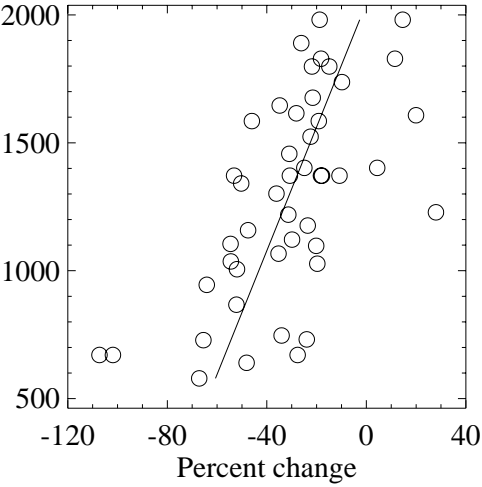

Fig. 4. Changing distribution of snow courses over time, and relationships of trends to elevation. (a) Number of snow courses reporting 1 April data (dotted line) for each year; for each starting year, number of snow courses at least $80 \%$ complete over the period of record (thick solid line), and their mean elevation (long dashed line, arrow indicates right-hand axis). Note how the early snow courses were few and were at higher elevation. (b), (c), (e), (f) Dependence of linear trends in 1 April SWE on elevation, for different starting years through the end of the record (plus symbols in panel (b) indicate trends from 1930, and the vertical line is the best fit). (d) Scatterplot of mean 1 April SWE against elevation of all snow courses (open circles) and of snow courses available in 1940 (solid circles). The mean value for each set is indicated by the large circles; mean SWE changes by $26 \mathrm{~cm}$ and the mean elevation by $290 \mathrm{~m}$.

\section{Quantifying "the snowpack" of a mountain range}

Using observations to estimate the total snow in a mountain range at a given time is difficult for several reasons, which were discussed above in connection with the VIC simulation. In addition to concerns about whether point values are representative of a $10 \mathrm{~km} \times 12 \mathrm{~km}$ area, one must be very careful to recognize variations at larger scales along the mountain range - note the patchiness of coverage in Fig. 1, with some river basins well-sampled and others unsampled. We discuss the effects of sampling, area-weighting, and choice of starting date which also affects sampling.

\subsection{Sampling}

Ideally, an observationally derived estimate would balance spatial coverage with temporal longevity. However, another crucial factor, even more than horizontal coverage, is vertical coverage. As Fig. 4a shows, the number of long-term snow courses (those in existence by 1960 and still providing data in
2006) changed rapidly during the 1940s, so that the choice of a cutoff year (say 1945 or 1950) influences how many snow courses are available for analysis and their mean elevation. In particular, the mean elevation of the early snow courses was much higher before about 1945, when the mean elevation of available snow courses stabilized at about $1300 \mathrm{~m}$. This fact is crucially important in selecting snow courses because (a) according to our estimates from observations (below) and from VIC, roughly half the snowpack in the Cascades on 1 April lies at elevations below about $1240 \mathrm{~m}$, so it is important to adequately sample that half of the snowpack; and (b) low-elevation snowpack is much more sensitive to temperature than high-elevation snowpack (Mote, 2003; Mote et al., 2005; Hamlet et al., 2005), hence any response to regional warming is most likely to be detectable at lower elevations. Consequently, including only snow courses that were active before about 1945 leads to a considerable bias toward sampling high elevations. 
(a)
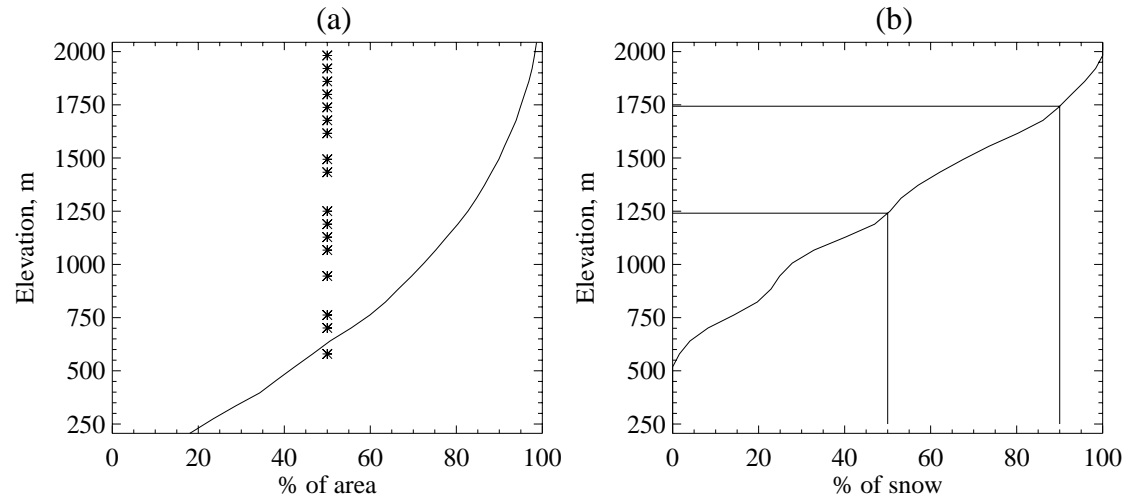

(c)

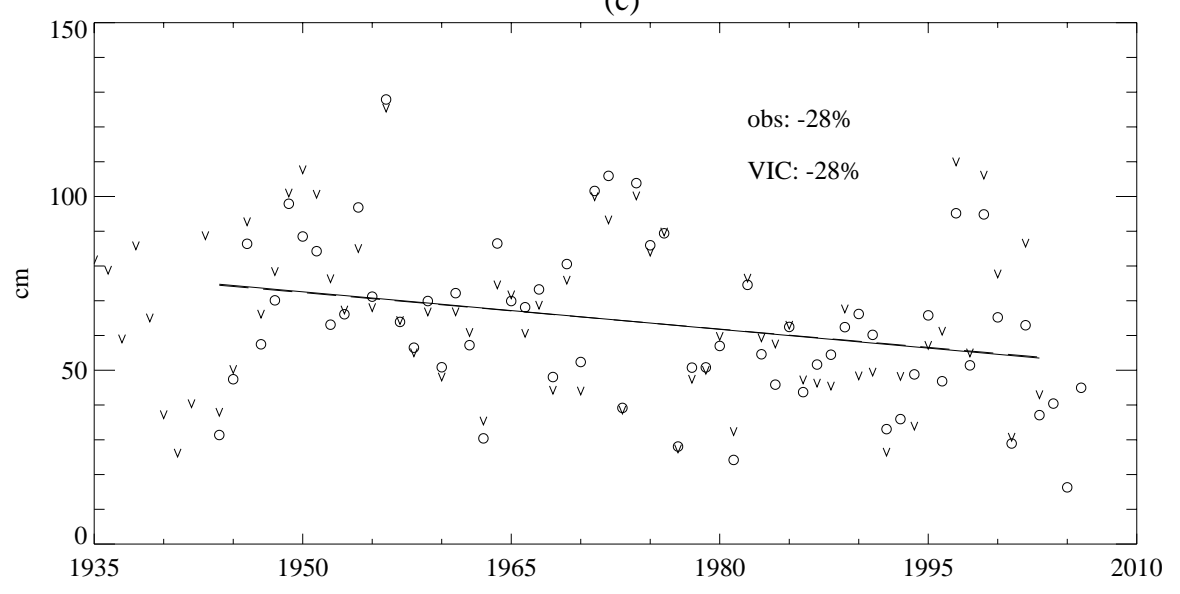

Fig. 5. Cumulative area (a) and SWE (b) as a function of elevation, for the Washington Cascades. In (a) the asterisks indicate the 60$\mathrm{m}$ elevation bands with at least one snow course. The curve in (b) is derived by smoothing and integrating the observed SWE-altitude relationship in Fig. 4d, and the lines indicate the 50th and 90th percentiles. (c) Regionally averaged 1 April SWE for observations (o) computed for the 1944-2006 snow courses using area-weighting and infilling of missing values with best-correlated time series, and VIC (v). The VIC values have been scaled to the mean observed SWE. Linear fits for observed (solid) and VIC (dashed) overlap.

Another consequence of the choice of starting date concerns the grand mean SWE for the available snow courses. High elevation snow courses also have higher mean SWE. Fig. $4 \mathrm{~d}$ shows the mean SWE and elevation for each of the snow courses, and shows how the lower elevations were poorly sampled before 1940 and much better sampled by 1945. The grand mean was lower in 1940 than in 1945.

As shown by Mote et al. (2005) and Mote (2006), the clearest signature of warming-induced changes in snowpack is that trends become less negative with increasing elevation. Figs. $4 \mathrm{~b}, \mathrm{c}$, e, and f show how consistently the trends depend on elevation, regardless (to first order) of starting year, with lines drawn to indicate how the trends depend quantitatively on elevation. The slopes of the lines are $59 \pm 28 \% / 1000 \mathrm{~m}$ for 1940 -present, $40 \pm 13 \% / 1000 \mathrm{~m}$ for 1950-present, $37 \pm 13 \% / 1000 \mathrm{~m}$ for 1960 -present, and $41 \pm 13 \% / 1000 \mathrm{~m}$ for 1970 -present. Trends 1930 -present (the plus symbols in the first panel) are about $10 \%$ higher than 1940-present for those six snow courses or aerial markers that date back to 1930 , but the small number and especially the lack of sampling below $1400 \mathrm{~m}$ prevents us from drawing conclusions about trends vs. elevation over the 1930-present period of record. The striking consistency in trends vs. elevation from one decade to the next, even for 1940 with very poor sampling below $1400 \mathrm{~m}$, emphasizes the pervasive role of warming in affecting trends in SWE at lower elevations, as will be shown below. From this analysis it is clear that the vertical fingerprint of warming has been detected in Cascades snowpack.

\subsection{Area-weighting with elevation}

The simplest approach to constructing a regional average is simply to average all of the snow course values each year. The area in each elevation band, however, decreases with elevation, so that even though low elevations have relatively little SWE per unit area (Fig. 3), they hold a large total quantity of snow, and are particularly sensitive to warming trends (Fig. 4). In order to estimate the importance of this effect, we construct elevation bands at $60 \mathrm{~m}$ vertical intervals, based 
on National Geophysical Data Center 2-min etopo2 digital elevation for the Washington Cascades, defined as the rectangle bounded by longitudes $122.75^{\circ}$ and $119^{\circ}$ west, latitudes $45.6^{\circ}$ and $49^{\circ}$ North. The hypsometric (cumulative area-altitude) relationship is shown in Fig. 5a along with the altitudes of the elevation bands containing snow courses used in constructing the 1944-2006 time series shown in Figs. 610. In Fig. 5b, the mean SWE from 1944 to 2006 at each snow course is multiplied by the area in that elevation band, and the resulting profile is interpolated to the elevation bands in which there are no snow courses, then smoothed slightly. The median elevation is only $640 \mathrm{~m}$, and half the SWE is found at elevations below $1241 \mathrm{~m}$, which is represented by only nine snow courses for the 1944-2006 time series (Table 1). Fully $90 \%$ of the snow on 1 April is found below $1743 \mathrm{~m}$, above which altitude most of the pre-1940s snow courses were located.

Using the area-weighting represented in Fig. 5b, we construct a time series of regionally averaged 1 April SWE (Fig. 5c). The strong weighting of the lower elevations, where observed declines have been larger, produces a larger linear trend, $-35 \%$ over the 1944-2006 period, than in the unweighted time series $(-28 \%$, Table 3 ; note that the trends shown in Fig. 5 are shown for 1944-2003 because the VIC simulation extended only to 2003). Furthermore, it brings the observed trend exactly into line with the VIC trend over the 1944-2003 period of the VIC simulation. In the succeeding analysis, we simply use the unweighted time series, recognizing that this probably produces an underestimate of temperature sensitivity and of linear declines.

\subsection{Effects of starting year}

For each starting year from 1927 to 1960, we composed a separate time series of total SWE for the Washington Cascades from available snow courses, with different cutoff years from 1935 to 1960 determining a different mix of snow courses. That is, time series 1 goes from 1927 to 2006 and includes acceptable snow courses that span 1927 to 2006; time series 2 goes from 1928 to 2006, etc. To be acceptable, a snow course had to have some data on or before the cutoff year, some data on or after 2003, and be at least $80 \%$ complete. Missing data (which totaled less than 7\%) were filled using linear regression against the best-correlated snow course, repeated if necessary with the next best correlated snow course. The ranking by correlation is rather different from the ranking by distance and is more physically realistic.

The full set of regionally averaged time series is shown in Fig. 6. As each snow course is added it changes the average SWE, as suggested in Fig. 4a, largely as a function of elevation of the new snow course. Additions beyond about 1950 make little difference, as suggested also by Fig. 4a. Three interdecadal peaks in SWE, centered on about 1952, 1973, and 1998, are interspersed with low points in the 1960s and one from the 1980 s to the early 1990 s, similar to the VIC

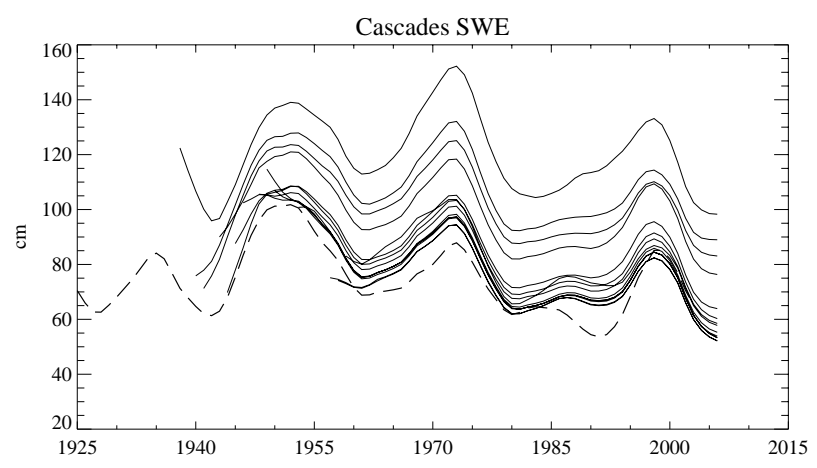

Fig. 6. Twenty-six different time series of regionally averaged SWE for the Washington Cascades are constructed by including all snow courses available by the date indicated, and smoothed (see Sect. 2 for details). Thick dashed curve shows VIC values from Fig. 3, scaled.

results repeated from Fig. 3a. Despite the fact that 2006 was a relatively good year for SWE, the very low years of 2001 and 2005 mean that the smoothed time series all end in a dip, which lies below the previous dip in around 1980 dominated by the very snow-poor years of 1977 and 1981 and other below-average years around that time. The ranking of snowiest or least snowy years (not shown) depends on which set of snow courses is chosen; for the curve composed of snow courses available by 1938 , the snowiest years are 1973, 1976, and 1956 (quite different from VIC), whereas for the 1956 curve the snowiest years are 1956, 1973, and 1999. Clearly any results derived from these regionally averaged time series will depend on judicious choice of time series for further analysis.

We now explore the correspondence of linear fits between VIC and observations for different starting points (Table 3). Each entry shows the trend from the starting year to 2003 (the last year of the VIC simulation); the observational estimates are for a changing mix of snow courses up to 1960. Most mid-century starting points yield a trend around $-25 \%$ for observations and VIC, with a range of about $-15 \%$ to $-35 \%$. Observed and VIC trends are within about $6 \%$ for starting points between 1945 and 1956; before 1945, the dearth of low-elevation snow courses affects the observed trends, as would be expected from Fig. 4. It is less clear why the trends diverge for starting points beyond the late 1950s, perhaps owing to land use change (e.g., encroachment of forests into snow courses). Trends are statistically significant (i.e. the 95th percentil estimate of the trend is negative) for observations for starting points only between 1945 and 1954, and for VIC only between 1942 and 1950. The 5th percentile estimates are mostly in the $-35 \%$ to $-55 \%$ range for observed starting points between 1942 and 1974, and for all VIC starting points between 1916 (not shown in the table) and 1974. Trends are generally positive, but not significant, for starting points after 1975. 
a.

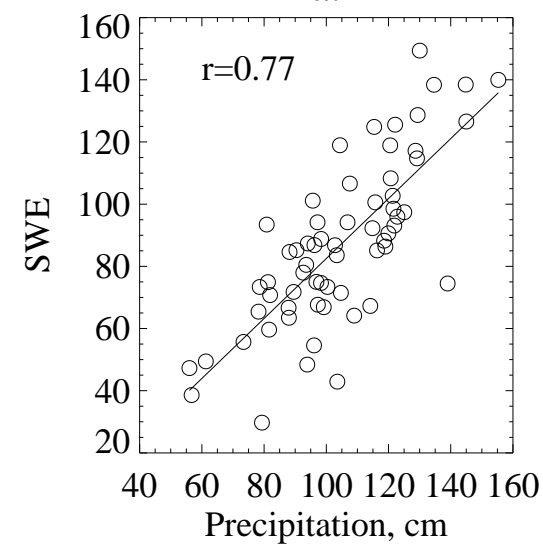

c.

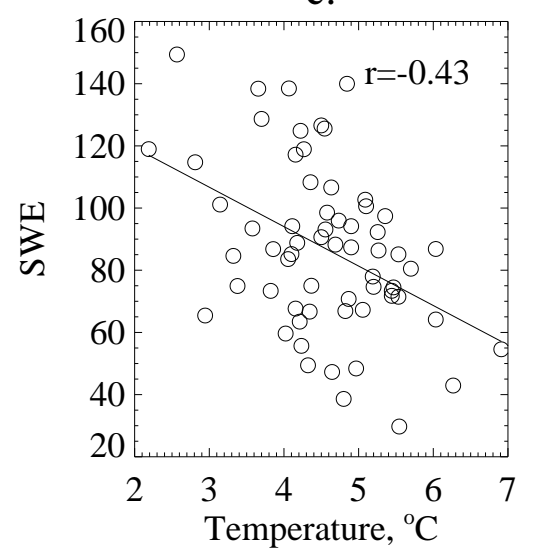

b. SWE from precipitation only

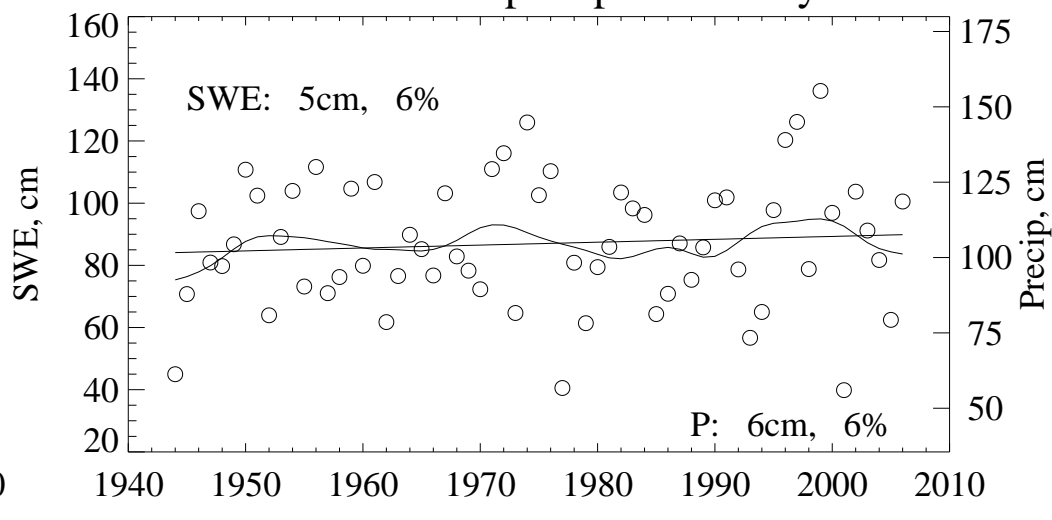

d. SWE from temperature only

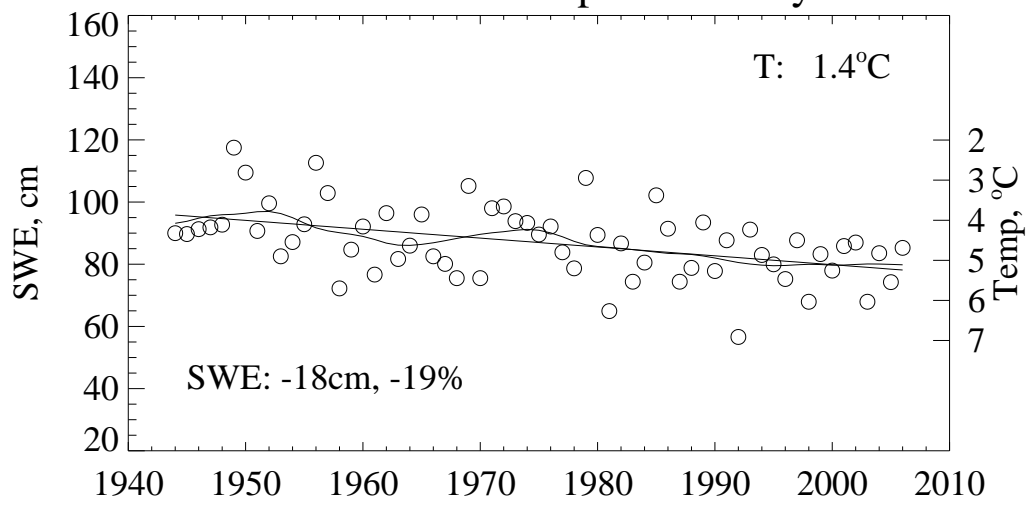

Fig. 7. Relationships between climate and regionally averaged SWE for the 1944-2006 period of record. Scatterplots and linear fit between regionally averaged 1 April SWE and November-March (a) precipitation and (c) temperature. Reconstruction of variability in SWE from (b) precipitation and (d) using the regression equation given in the text, along with trends. In panels (b) and (d) the left-hand axis refers to SWE and the right-hand axis refers to the climate variable, the loess fit is shown, and trends printed in each frame refer to the linear fit over the 1944-2006 period of record.

With the goal of characterizing the variability over as long a time as possible without too severely underemphasizing low elevations, we primarily use the time series starting in 1944. From Table 3 it is clear that this is a fairly conservative estimate of the trends; combined with our conservative choice regarding area-weighting, the computed trends here are likely on the small side.

\subsection{Regression analysis with temperature and precipitation}

Complementing the analysis of the temperature-only VIC simulation presented in Sect. 4, we use empirical relationships between 1 April SWE from each snow course and reference time series for temperature and precipitation in November through March, roughly as in Mote (2006). For this analysis through 2006, US Historical Climate Network (USHCN) data were not available for 2006 , so instead we use the Climate Division data for Washington Climate Division 4 (west slopes Cascades and foothills). As a first step in understanding the linear relationships between SWE and the climate variables, we compute the correlations between 1 April SWE and Nov-Mar mean temperature and precipitation, for different periods of analysis (not shown). Consistent with Fig. 4 and the sensitivity of SWE at lower elevations to temperature, the correlations change as the starting date moves later and more low-elevation snow courses are included: the correlation of regionally averaged SWE with precipitation drops from around 0.8 to 0.7 , and the correlation with temperature changes substantially from -0.3 to about 0.5. The scatterplots of the 1944-2006 SWE time series with precipitation and temperature are shown in Fig. 7a and 7c.

Next, the climate data are used in multiple linear regression to estimate the regionally averaged snowpack for the 1944-2006 time series. 
Regression analysis against November-March precipitation and temperature is performed, as in Mote (2006):

$\operatorname{SWE}(\mathrm{t})=\mathrm{SWE}_{0}+\mathrm{a}_{\mathrm{T}} \mathrm{T}(\mathrm{t})+\mathrm{a}_{\mathrm{P}} \mathrm{P}(\mathrm{t})+\varepsilon(\mathrm{t})$

where $\operatorname{SWE}(\mathrm{t})$ is the 1 April SWE in year $\mathrm{t}, \mathrm{SWE}_{0}$ is the mean SWE, $\mathrm{a}_{T}$ and $\mathrm{a}_{P}$ are the regression coefficients for temperature and precipitation respectively, and $\mathrm{T}(\mathrm{t})$ and $\mathrm{P}(\mathrm{t})$ are the values of temperature and precipitation in year $t$, and finally $\varepsilon(\mathrm{t})$ is the residual. We can then also define $\mathrm{S}(\mathrm{t})=\mathrm{SWE}_{0}+\mathrm{a}_{T} \mathrm{~T}(\mathrm{t})+\mathrm{a}_{P} \mathrm{P}(\mathrm{t})$, that is, the time series generated directly from the climate data. The correlation between $\operatorname{SWE}(\mathrm{t})$ and $\mathrm{S}(\mathrm{t})$ is 0.88 , and the correspondence is quite good in most years, though the trend in $\mathrm{S}(\mathrm{t})$ is less than observed for a number of possible reasons (mainly that when variance is partitioned between a deterministic and a stochastic component, the regressed extreme values tend to be less extreme and the slope of the fitted trend is consequently also reduced). There may also be some errors in the long-term trends in the climate division data.

Using the regression approach permits a separation of the effects of temperature $\mathrm{SWE}_{0}+\mathrm{a}_{T} \mathrm{~T}(\mathrm{t})$ and precipitation $\mathrm{SWE}_{0}+\mathrm{a}_{P} \mathrm{P}(\mathrm{t})$ (Figs. $7 \mathrm{~b}$ and $7 \mathrm{~d}$ ). This analysis shows that to first order the long-term change is a result of warming, with precipitation adding noise that makes the trend detection more difficult, especially on shorter time periods (see Table 3). This result is very consistent with the results of the two experiments shown in Fig. 3. For the 1956-2006 time series (not shown), the observed decline is $27 \%$, the trend in $\mathrm{S}(\mathrm{t})$ is $-15 \%$, the trend in $\mathrm{a}_{P} \mathrm{P}$ is $0 \mathrm{~cm}$ or $2 \%$ and the trend in $\mathrm{a}_{T} \mathrm{~T}$ is $-5 \mathrm{~cm}$ or $-17 \%$. Hence, even starting at one of the wettest years in the record, the results are similar: the trend is dominated by $\mathrm{a}_{T} \mathrm{~T}(\mathrm{t})$.

4.5 Further distinguishing roles of temperature and precipitation

The ratio of 1 April SWE over November-March precipitation (Fig. 8) shows what fraction of precipitation falling from November through March remains on the ground on 1 April, what we might call the storage efficiency. A useful metric for the pattern expected from regional warming, this ratio has declined by $28 \%$ for observations and also by 28\% for VIC, over the common period of record 1944-2006. Note that because the precipitation measurements come from weather stations, which are almost all located at low elevations where less precipitation falls, the actual precipitation was multiplied by 1.5 to reflect high-elevation enhancement of precipitation (this factor, estimated from precipitation records at the only two long-term high-elevation sites [Paradise and Stevens Pass] and nearby lower-elevation sites [Longmire and Monroe, respectively] does not affect the computed trends). Storage efficiency was worst for 2005 , when much of the winter precipitation fell in three warm wet storms in what was otherwise not an exceptionally warm winter (Fig. 7b, d).

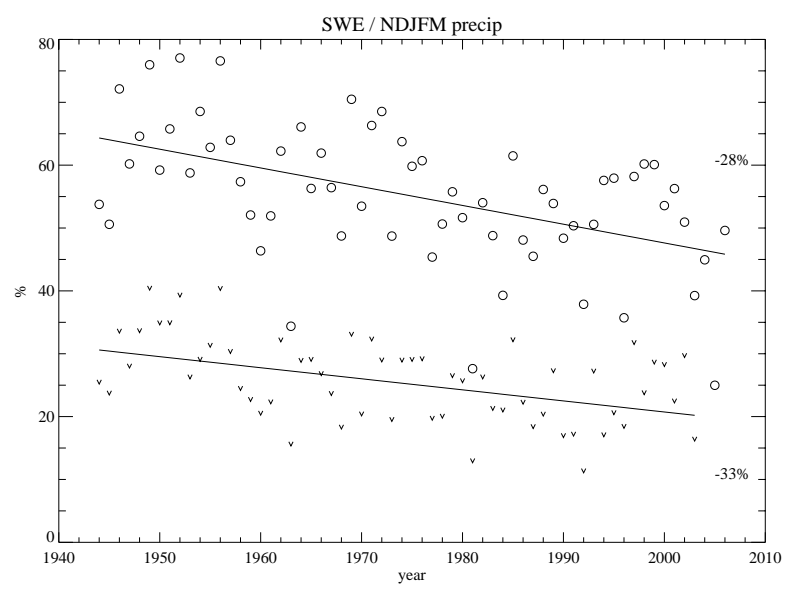

Fig. 8. "Storage efficiency," the ratio of 1 April SWE to NovemberMarch precipitation, with linear fit, for observations (o) 1944-2006 and VIC (v) simulation 1944-2003. The average storage efficiency in VIC is lower because the domain includes a lot of low-elevation grid points, but the percentage changes are similar.

Yet another way to emphasize the role of warming recognizes that the fundamental pattern of change in SWE in simulations of warming is a pronounced loss at lower elevations. We use the same set of snow courses from 1944 as in Figs. 7 and 8 , and construct time series of average SWE at elevations above $1200 \mathrm{~m}$ ("high") and below $1200 \mathrm{~m}$ ("low"). The ratio of low to high elevation SWE is shown in Fig. 9, along with a linear fit. The slope parameter is statistically significant.

\section{Discussion and conclusions}

When observations are weighted by the area of each elevation band, there is a remarkable congruence between observed and modeled estimates of regionally averaged SWE (Fig. 5). This is all the more remarkable because the point measurements of the observations and the gridded values of the model are fundamentally different quantities, and furthermore the observations are potentially affected by a different set of time-varying biases (e.g., land cover change). Both the observationally derived and modeled estimates of total 1 April SWE have strengths and weaknesses. The modeling produces robust spatially distributed estimates of SWE and the resulting streamflow agrees well with observations, as does the simulated snow for roughly three-quarters of the observed snow courses; on the other hand, VIC requires interpolated temperature and precipitation which may not always accurately reflect the daily values experienced in the remote mountains. The observed values are actual measurements but may be influenced by site changes like canopy growth, and their spatial distribution is so sparse that areally averaged estimates are sensitive to choices about which snow courses to include (see also Molotch and Bales, 2005). Such choices 


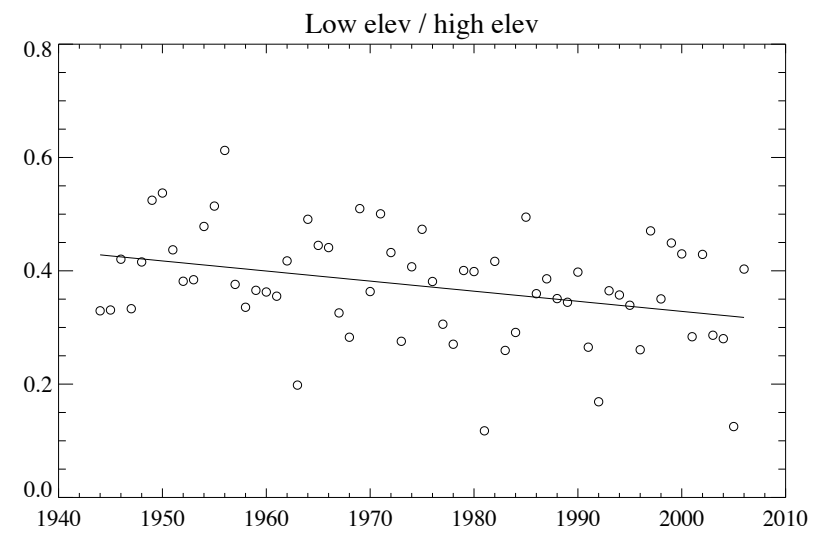

Fig. 9. Ratio of 1 April SWE at low-elevation $(<1200 \mathrm{~m})$ snow courses to SWE at high-elevation $(>1200 \mathrm{~m})$ snow courses. With the linear fit, the ratio has declined from 0.42 to 0.33 from 1944 to 2006; note also that in 2005 and 1981 the low elevations had less than $15 \%$ as much SWE as the high elevations.

are especially important with respect to elevation, since (1) a great deal of snow on 1 April lies at relatively low elevations that are represented by very few snow courses and (2) longterm warming trends disproportionately affect low elevation snow (Fig. 4).

The smooth curves in Figs. 3 and 6 emphasize that there is substantial variability in 1 April SWE on timescales longer than several years. During the period of adequate instrumental coverage (1944-2006) three relatively snowy periods have occurred; in the observations and the VIC simulation, each of these had a slightly lower peak than the last and the dips in between have also declined over time. In addition, the combination of VIC simulation and observations for recent years suggests that the most recent dip is the lowest point since 1915, even including the exceptional drought periods of the 1930s and early 1940s.

Within a decade or so of 1955 , selection of starting date does not greatly influence the linear declines computed from observations, and most trends in this time window are statistically significant. The linear decline of 1 April SWE with ending point 2006 and from starting points between 1916 and 1970, calculated either with VIC data or observations (the latter starting no earlier than 1944 to ensure adequate sampling of lower elevations), is roughly $-15 \%$ to $-35 \%$ and mostly around $-25 \%$ (Table 3). Area-weighting the observations produces larger declines. The drawback of using linear fits is that they obscure interesting and significant features like the local maximum in SWE in the late 1990s.

Fluctuations and trends in temperature and precipitation play distinct roles in the behavior of these time series. Rising temperatures have clearly dominated in determining the regionally averaged trend in SWE over periods longer than about 30 years, as is evident in (a) the VIC simulation with
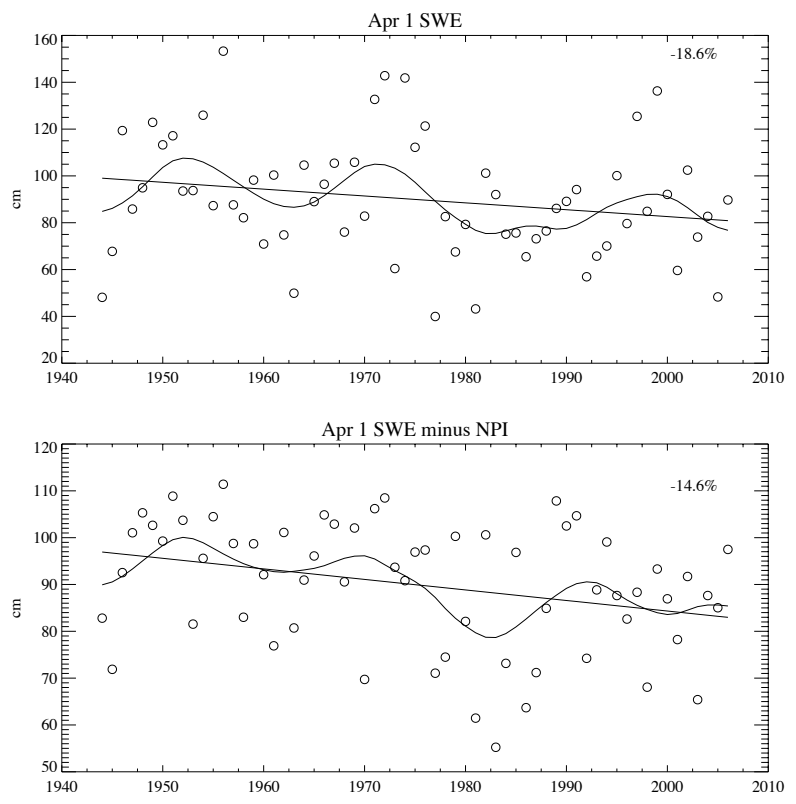

Fig. 10. Variability and trend in 1 April SWE (1944-2006 time series), top, and with NPI regression subtracted (bottom).

fixed precipitation (Fig. 3b); (b) the regression analysis (Fig. 7); (c) the declining "storage efficiency" (Fig. 8); (d) the strong dependence of trends on elevation (Fig. 4); and (e) the declining ratio of low elevation to high elevation snowpack (Fig. 9). Precipitation produces much of the interannual variability but plays little role in trends except over short time periods (say, post-1970), and linear trends in precipitation are not statistically significant over any period in contrast to those of temperature.

Further interpretation is required though. What is one to make of the positive (but not significant) trends in SWE since the early 1970s? What roles have Pacific decadal variability and human-induced global warming played in these changes?

The subject of natural variability and its connection to variations and trends in western snowpack has been examined by Mote (2006), Stewart et al. (2005), and Clark et al. (2001). Mote (2006) regressed individual time series of SWE in the West on the North Pacific Index (NPI), an atmospheric index sensitive to variability of both El Niño/Southern Oscillation (ENSO) and the Pacific Decadal Oscillation (PDO), and found that 10-60\% of trends in SWE at snow courses in the Pacific Northwest (PNW) could be explained by the NPI, a larger fraction than for the PDO index itself. Response to NPI is characterized by an out-of-phase relationship between the PNW and the Southwest, and the strong positive trends in precipitation in the Southwest since 1950 (chiefly the result of a severe drought in the 1950s and early 1960s) overwhelmed the influence of rising temperatures there, producing positive trends in SWE at most sites. 
Could the trends in SWE be solely a response to a step change in the PDO in 1977? There are three problems with this view. First, the phase of the PDO is not accurately represented by constant values that change sign every few decades, and in particular the PDO index has not shown a clear preference for positive or negative values in the past 10 years, nor a strong correspondence to PNW SWE. Second, even with the NPI or PDO regressed out of the time series of SWE, a substantial negative trend in 1 April SWE remains and in fact becomes statistically significant. We correlate and regress the 1944-2006 time series of 1 April SWE shown in Fig. 6 with November-March NPI: the correlation is 0.54 , so NPI plays a significant role in interannual variability, but with NPI regressed out, the trend changes only from $-24 \%$ to $-16 \%$ (Figure 10). The coefficient of variation is reduced as well. Third, if the period since 1997 or 1999 has been a negative phase PDO it does not explain the very low snow years of 2001 and 2005, nor the much lower storage efficiency for most years since 1997. Furthermore, it is not yet clear what role greenhouse gases may have played in changes in the NPI; some studies suggest that the observed changes in natural patterns like ENSO may themselves be related to anthropogenic climate change (e.g., Guilyardi 2006), in which case "removing" the NPI as was done above may remove both anthropogenic and natural factors.

Could emerging human influence on climate produce rises in PNW precipitation that completely offset losses in snowpack produced by temperature? A useful metric for emerging human influence is the logarithm of global $\mathrm{CO}_{2}$, a rough approximation of the radiative forcing and hence the climatic influence of human activity. Regression of $\ln \left(\mathrm{CO}_{2}\right)$ on temperature produces a fairly large coefficient, explaining much of the observed linear trend. However, for precipitation the regression is close to zero. This hypothesis also is inconsistent with the twenty scenarios of Northwest climate produced under the auspices of the IPCC and analyzed by Mote et al. (2005b), which suggest only modest changes (a few $\%$ ) in winter precipitation in response to rising greenhouse gases. This is consistent with evidence in the literature that at least on the scale of the West a human influence on air temperature can be detected (e.g., Stott, 2003) but also that neither globally nor at middle latitudes can a human influence on precipitation be detected (Gillett et al., 2004; see also Zhang et al. 2007). In simulations with the VIC hydrology model, even large increases in winter precipitation were not sufficient to offset losses of SWE in the Cascades associated with warming (e.g., Hamlet and Lettenmaier, 1999). The extremely high seasonal precipitation in 1997 and 1999, which helped make the most recent 10 -year period the wettest period in the instrumental record and produced the peak in the smooth curve in Figs. 3 and 6, only managed to raise 1 April SWE to about half the value of the $\sim 1950$ peak.

We are left, then, with the conclusions that (1) rising temperatures are the primary factor in the observed declines in SWE; (2) fluctuations in precipitation have partially masked this signal; (3) while a quantifiable role of Pacific decadal variability in these declines can be found, the warming trends are largely unrelated to Pacific climate variability and strongly congruent with trends expected from rising greenhouse gases.

Acknowledgements. Snow course measurements provide unique climate records of the mountainous regions of the West, and we wish to thank heartily the dedicated snow surveyors of decades past and of today for making the measurements described herein, and NRCS for providing the data. We also thank R. Norheim for constructing the map in Fig. 1, and M. Stoelinga, D. Hartmann, R. Wood, H. Harrison, D. Lettenmaier, K. Redmond, N. Mantua, and three anonymous reviewers for helpful comments on an earlier version of this manuscript. This publication was funded by the Joint Institute for the Study of the Atmosphere and Ocean (JISAO) at the University of Washington under NOAA Cooperative Agreement No. NA17RJ1232, Contribution \#1411.

Edited by: B. van den Hurk

\section{References}

Bretherton, C. S., Widmann, M., Dymnikov, V. P., Wallace, J. M., and Blade, I.: Effective number of degrees of freedom of a spatial field, J. Climate, 12, 1990-2009, 1999.

Cherkauer, K. A. and Lettenmaier, D. P.: Simulation of spatial variability in snow and frozen soil, J. Geophys. Res., 108, 8858, doi:10.1029/2003JD003575, 2003.

Cleveland, W. S.: Visualizing Data, Hobart Press, Summit, N.J., 1993.

Gillett, N. P., Weaver, A. J., Zwiers, F. W., and Wehner, M. F.: Detection of volcanic influence on global precipitation, Geophys. Res. Lett., 31(12), L12217, doi:10.1029/2004GL020044, 2004b.

Guilyardi, E.: El Niño-mean state-seasonal cycle interactions in a multi-model ensemble, Clim. Dynam., 26, 329-348, 2006.

Hamlet, A. F. and Lettenmaier, D. P.: Production of temporally consistent gridded precipitation and temperature fields for the continental U.S., J. Hydrometeorol., 6(3), 330-336, 2005.

Hamlet, A. F., Mote, P. W., Clark, M. P., and Lettenmaier, D. P.: Effects of temperature and precipitation variability on snowpack trends in the western U.S., J. Climate, 18, 4545-4561, 2005.

Karl, T. R., Williams Jr., C. N., Quinlan, F. T., and Boden, T. A.: United States Historical Climatology Network (HCN) Serial Temperature and Precipitation Data, Environmental Science Division, Publication No. 3404, Carbon Dioxide Information and Analysis Center, Oak Ridge National Laboratory, Oak Ridge, TN, 389 pp., 1990.

Lemke, P., Ren, J., Alley, R. B., Allison, I., Carrasco, J., Flato, G., Fujii, Y., Kaser, G., Mote, P., Thomas, R. H., and Zhang, T., Observations: Changes in Snow, Ice and Frozen Ground. Chapter 4 in: Climate Change 2007: The Physical Science Basis, Contribution of Working Group I to the Fourth Assessment Report of the Intergovernmental Panel on Climate Change, edited by: Solomon, S., Qin, D., Manning, M., Chen, Z., Marquis, M., Averyt, K. B., Tignor, M., and Miller, H. L., Cambridge University Press, Cambridge, United Kingdom and New York, NY, USA, 2007. 
Liang, X., Lettenmaier, D. P., Wood, E. F., and Burges, S. J.: A simple hydrologically based model of land surface water and energy fluxes for general circulation models, J. Geophys. Res., 99(D7), 14415-14428, 1994.

Molotch, N. P. and Bales, R. C.: Scaling snow observations from the point to the grid element: Implications for observing network design, Water Resour. Res., 41, W11421, doi:10.1029/2005WR004229, 2005.

Mote, P. W.: Climate-driven variability and trends in mountain snowpack in western North America, J. Climate, 19, 6209-6220, 2006.

Mote, P. W., Hamlet, A. F., Clark, M. P., and Lettenmaier, D. P.: Declining mountain snowpack in western North America, B. Am. Meteorol. Soc., 86, 39-49, 2005.
Regonda, S., Rajagopalan, B., Clark, M., and Pitlick, J.: Seasonal cycle shifts in hydroclimatology over the Western US, J. Climate, 18, 372-384, 2005.

Salathé, E. P., Mote, P. W., and Wiley, M. W.: Considerations for selecting downscaling methods for integrated assessments of climate change impacts, Int. J. Climatol., 27(12), 1611-1621, doi:10.1002/joc.1540, 2007.

Stott, P. A.: Attribution of regional-scale temperature changes to anthropogenic and natural causes, Geophys. Res. Lett., 30, 1724, doi:10.1029/2003GL017324, 2003.

Zhang, X., Zwiers, F. W., Hegerl, G. C., Lambert, F. H., Gillett, N. P., Solomon, S., Stott, P. A., and Nozawa, T.: Detection of human influence on twentieth-century precipitation trends, Nature, 448 , 461-465, doi:10.1038/nature06025, 2007. 